\title{
Arabic Learners' Production of Regular English Past Tense Verbs
}

\author{
Baraa A. Rajab \\ English Language Institute, King Abdulaziz University, Jeddah, Saudi Arabia \\ E-mail: brajab@kau.edu.sa
}

Received: November 15, 2021 Accepted: December 12, 2021 Published: December 16, 2021

doi:10.5296/ijl.v13i6.19205

URL: https://doi.org/10.5296/ijl.v13i6.19205

\begin{abstract}
Previous studies show that second language (L2) learners of English sometimes produce the verb with proper past tense inflectional morphology as in help[t] and sometimes repair the cluster, as in helpø or hel[pəd]. Complicating matters, these studies focused on L2 learners whose native languages disallowed codas or had very restricted codas. Thus, it is difficult to tell whether any problems in producing past tense morphology are due to first language L1-transferred coda restrictions, or an inability to acquire the abstract feature of past tense. To rule out native language syllable structure interference, this paper aims to examine the production of the English regular past tense verb by Arabic L1 ESL learners, a language that allows complex codas. The paper also examines the role of a phonological universal, the Obligatory Contour Principle (OCP) that disallows two adjacent similar sounds, and its effect on learners' production. The data come from twenty-two English as a Second Language (ESL) students at three levels of proficiency. The task was a sentence list eliciting target clusters in past tense contexts that violate manner in OCP: fricative + stop ([st], [ft]) vs. stop + stop ([pt], $[\mathrm{kt}]$ ). Results show that L1 Arabic speakers have difficulty in producing past tense morphology, even though their L1 allows complex codas. Fricative + stop clusters are repaired (epenthesis/deletion) at a lower rate (low $=25.71 \%$, intermediate $=6.6 \%$, high $=11.11 \%$ ) than stop + stop clusters $($ low $=57.14 \%$, intermediate $=40.27 \%$, high $=22.91 \%)$. The higher rate of repair is clear in stops + stop clusters suggesting that learners abide by phonological universals and prefer not to violate OCP. Finally, proficiency level has an effect on target-like production, as higher-proficiency learners produce past-tense morphology at a higher rate than lower-proficiency learners. Together, these results indicate that L1 transfer is not the only source of difficulty in the production of past tense morphology, and that the abstract feature of tense is problematic, particularly at the early stages of ESL development.
\end{abstract}

Keywords: Arabic L1 speakers, L2 learners, Obligatory Contour Principle (OCP), Tense morphology 


\section{MlMacrothink}

\section{Introduction}

The variability in the production of inflectional morphology by second language learners has been a well-studied issue in L2 research. Second language learners of English show an inconsistency in marking the regular past tense verb with proper inflection. For example, an L2 learner might produce I help[t] my sister last night with proper past tense marking. At other times, the learner might produce I skip $\phi$ school yesterday with missing tense marking on the verb. Other times second language learners modify the cluster by adding an epenthetic vowel I hel[pad] John. Various studies propose different reasons behind the variability of inflectional morphology (Goad et al., 2003; Lardiere, 2003; Prévost \& White, 2000; Solt et al., 2004).

This paper aims to investigate the production of the English regular past tense morpheme by L2 learners. The study focuses on the different phonological factors that might contribute to the variability. In addition, the study will seek to explore if phonological universals impact production. This paper is organized as follows; section 2 discusses the linguistic background, section 3 summarizes previous studies, which leads to the research question proposed in section 4. Section 5 explains the methodology used in this study, section 6 explores the results and discussion of the results. Section 7 concludes.

\section{Linguistic Background}

The present study investigated data from Arabic L2 speakers of English. The study focuses on the production of the regular English past tense morpheme 'ed'. The past tense morpheme in English has three variations (allomorphs) /t/, /d/ or /ad/. The addition of the English past tense may create complex codas of CC, or CCC (Kreidler, 2008). One of the key facts in this study is that Arabic allows for word-final complex codas consisting of CC, such as [rapt] 'to tie' (Ryding, 2005). Table 1 below summarizes Standard Arabic's syllable structure (adapted from Holes, 2004).

Table 1. Standard Arabic Syllable Structure

\begin{tabular}{|c|c|c|c|}
\hline Syllable type & Arabic example & Gloss & Notes \\
\hline $\mathrm{CV}$ & [la] & no & $\begin{array}{l}\text { The most common syllable structure in } \\
\text { Arabic }\end{array}$ \\
\hline CVV & [leI.sa] & not & \\
\hline $\mathrm{CVC}$ & [ka.tab] & He wrote & \\
\hline CVVC & [kaf.taan] & $\begin{array}{l}\text { A type of } \\
\text { material }\end{array}$ & $\begin{array}{l}\text { They are considered heavy syllables } \\
\text { and are restricted to word-final } \\
\text { positions }\end{array}$ \\
\hline $\mathrm{CVCC}$ & [ka.tapt] & $\begin{array}{l}\text { I wrote - } \\
\text { past }\end{array}$ & \\
\hline
\end{tabular}


Looking at Table 1 above, Arabic allows complex codas consisting of CC. We expect to find positive transfer from L1 to L2; therefore, learners will face no difficulty in producing the regular past tense in English that forms a CC coda. However, this is not the case. Arabic learners have problems producing the regular English past tense. Since 'transfer' does not account for the learner's variability in production, a look into a phonological universal, the Obligatory Contour Principle (OCP), might help account for their production. McCarthy (1986) defines the principle of OCP as in (1):

\section{(1) Obligatory Contour Principle}

"at the melodic level, adjacent identical elements are prohibited" (p. 208).

The following section will explore the literature and previous studies related to the variability of inflectional morphology.

\section{Literature Review}

The review of the literature will be structured as follows: First, studies on morphological variability in second language will be discussed. A discussion on the role of phonology in second language is presented in section 2. Finally, an overview of studies on OCP effects in second language is provided.

\subsection{Morphological Variability in Second Language}

Previous studies in second language acquisition of inflection (especially in tense and agreement) focus on the association or disassociation between syntax and morphological variability. Some researchers propose that the absence or the variable suppliance rate of inflection is due to syntactic impairment in the IL grammar. This syntactic impairment leads to the failure of acquiring feature strength or functional projections (IP, AgrP, TP) in the L2. Some researchers propose that this impairment is permanent (Hawkins \& Chan, 1997; Meisel, 1991) and others propose that it is temporary and that learners will gradually acquire functional projections (Vainikka \& Young-Scholten, 1996). On the other hand, other researchers propose that there is no impairment in the syntax. Functional projections and feature strength are present in the L2 learner's interlanguage, but variability of inflectional morphology surfaces due to failure of representation (such as communication pressure) or "mapping problems" and failure to access (Grondin \& White, 1996; Haznedar \& Schwartz, 1997; Lardiere, 2003; Prévost \& White, 2000). The absence or variability in the production of inflectional morphology does not entail impairment in the syntax.

One important study is Lardiere (2003) case study on Patty, a native Chinese speaker that resided in the United States for over 18 years. Lardiere (2003) gathered the data from three recordings of spontaneous speech production during three different intervals of time. She examined Patty's production in past tense marking and pronominal case marking. Patty's production is about 35\% suppliance of past tense in obligatory contexts in all three recordings. On the other hand, Patty's suppliance of nominative case in obligatory contexts is $100 \%$ in all three recordings. Patty's data shows that the production of the past tense has stabilised and she has acquired TP from her accurate suppliance of nominative case suggesting that she has 
tense and agreement features. Lardiere (2003) proposes that Patty's problems are not due to any deficit in functional features or the syntactic domain but resides in morphological mapping or "mapping problems" to the phonological component.

In a similar study based on the disassociation between syntax and the use of inflection is a study conducted by Prévost and White (2000). They claim that L2 learners have no impairment in their features or functional projections. The L2 learners' variable use of inflection is due to failure of access of the correct features. They study the use of inflectional morphology (tense and agreement) by four L2 learners of French and German. The data was gathered over a period of two to three years from spontaneous production. Their aim was to look at finite verbs vs. non-finite verbs, verb placement, verbal agreement (person and number) and, in French, subject clitic agreement. Results of their study show that L2 learners are distinguishing between finite and non-finite inflectional morphology. They do not substitute finite forms for non-finite forms. In addition, L2 French learners show proper subject clitic agreement. Based on their findings in the study, Prévost and White (2000) conclude that L2 learners are in fact distinguishing between the knowledge of surface morphology and abstract features. The L2 learners' variability in the use of inflectional morphology is not due to lack of functional projections or features because they are not associated with one another. They have problems with surface morphological realizations of particular forms because access to those fully specified features is "blocked". The blockage is due "to processing reasons or communication pressure" (Prévost \& White, 2000, p. 129).

The above studies seem to support the claim that the use of inflection is not associated with syntactic impairment. However, these studies conclude that variability is due to other factors. Lardiere (2003) study concludes that Patty's problem in overtly marking the past tense is due to mapping problems between the feature itself and the surface realization. She also concludes that phonological restrictions might prevent Patty from marking the past tense. In a later study, Lardiere (2003) mentions that Patty's written production of past tense shows different results. Patty's written production marked almost $77 \%$ suppliance on regular past tense verbs. Since the studies mention the need to look for other factors contributing to this variability, a closer look into studies based on phonological factors will be taken into consideration in the following section.

\subsection{The Role of Phonology}

Many studies investigate the phonological factors that contribute to the variability of L2 inflectional morphology. One important study was conducted by Bayley (1996). He examines the patterns that linguistic and social constraints have on final $-\mathrm{t} / \mathrm{d}$ deletion. Bayley (1996) claims that the $-\mathrm{t} / \mathrm{d}$ variable is sensitive to many factors. One of the factors that contribute to $-t / d$ deletion is the phonological environment (syllable stress, number of C's on a cluster, grammatical category, following segments and agreement in voicing). In addition, social factors (speech style, speaker age, English proficiency, social network) have an effect on $-\mathrm{t} / \mathrm{d}$ deletion. He looks at these factors and analyses how they may/may not contribute to the deletion of $-\mathrm{t} / \mathrm{d}$ in the interlanguage of second language learners.

Bayley (1996) collected data from Chinese native speakers learning English as an L2. From 
the data collected, he built a database consisting of all regular consonantal non-syllabic participles and preterits, and all marked past tense semi weak verbs. The data was coded to test the effect of linguistic factors, social and developmental factors mentioned above. The data was analysed using VARBRUL.

The results show that $-\mathrm{t} / \mathrm{d}$ deletion is affected by grammatical category, preceding segment, following segment, and voicing agreement with the preceding segment. Participants are less likely to delete $-\mathrm{t} / \mathrm{d}$ if the following or preceding segment is a sonorant. In terms of voicing, if the preceding segment agrees in voicing with $-\mathrm{t}$ or $-\mathrm{d}$, deletion occurs. For the grammatical category, participants' speech favours $-\mathrm{t} / \mathrm{d}$ absence in preterits but not monomorphemes. For the social factors, English proficiency, social network, and speech style also have an effect on $-t / d$ deletion. Based on his findings, Bayley (1996) claims that when there are multiple constraints on the surface marker, it is difficult to examine to what extent production reflects acquisition. He also claims that the analysis of phonological and grammatical processes in $-t / d$ deletion reflects the differences between acquisition and production but does not explain what second language learners need to do in order to reach native-like performance. Bayley (1996) concludes that learners must acquire categorical inflection markings and a formal system of boundary constraints to achieve native-like performance.

Taking a similar approach to Bayley (1996), Solt et al. (2004) investigate the perception and production of the regular English past tense morpheme in L2 learners of English. The aim behind their study was to understand the "extra-syntactic factors" that caused the variability in the use of the regular past tense morpheme in L2 English. They studied 68 adult learners of English (two proficiency levels) with different L1 backgrounds (Spanish, Arabic, Mandarin, Cantonese, Turkish, Russian, Ukrainian, and French Creole). Their aim was to test the participants' perception and production of regular past tense in English across its three allomorphs. The results in the perception task shows that L2 learners are able to perceive the syllabic past tense [əd] (90\% for high proficiency, $85 \%$ for low proficiency) better than non-syllabic ones $[\mathrm{t}]$ and $[\mathrm{d}]$. Between $[\mathrm{t}]$ and $[\mathrm{d}]$, both levels of participants showed higher rate of accuracy in $[\mathrm{t}]$ (high $=70 \%$, low $=61 \%$ ) than the allomorph $[\mathrm{d}]$ (high $=62 \%$, low $=$ $58 \%$ ). For the production task, participants were asked to produce the past tense in a written task containing contextual clues. The results of this task show that high proficiency learners were able to produce the regular past tense morpheme across its three allomorphs (average of 90\%). The participants in this group were able to draw on contextual clues in the task to produce the proper morphology. The low proficiency learners scored around 50\% across the three allomorphs. Based on their findings, Solt et al. (2004) propose what they call a "systematic perceptual deficit" which is a barrier to perceive and produce target-like past tense morphology. They also add that L2 learners cannot produce what they cannot perceive. Since the participants did better in perceiving and producing the allomorph [əd], Solt et al. (2004) claim that when adding the past tense morpheme to English verbs, if the result is a cluster such as [st] or [vd], learners will have trouble perceiving the cluster therefore not produce it. On the other hand, when the result is an extra syllable like [dəd] L2 learners of English will perceive it and produce it at higher rates.

Goad et al. (2003) take a different phonological approach in analysing their data. They 


\section{Macrothink}

propose the "Prosodic Transfer Hypothesis" (Goad et al., 2003, p. 246). The Prosodic Transfer Hypothesis predicts that the prosodic structure of the learner's L1 is transferred in to their L2 and constrains the new IL grammar. They study a group if Mandarin speakers learning English as an L2. They propose that the difference in English and Mandarin prosodic word structure results in the failure to supply proper English inflectional morphology.

Goad et al. (2003) explain the difference in prosodic structure between English and Mandarin Chinese. They propose that English's tense and agreement join at the Prosodic word (PWd) level making it external as in (Figure 1) (Goad, et al, 2003, p. 248):

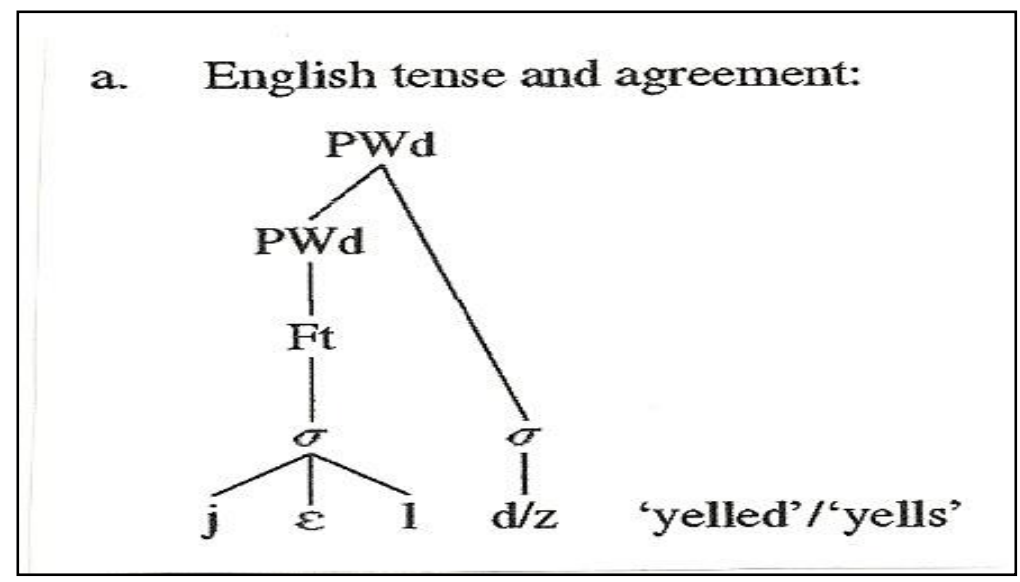

Figure 1. English tense and agreement

On the other hand, Mandarin aspect joins in a different way than English. The structure in Figure 1 is not available in Mandarin. Aspect in Mandarin joins at the Foot (ft) level making it internal such as (Figure 2) (Goad et al., 2003, p. 248):

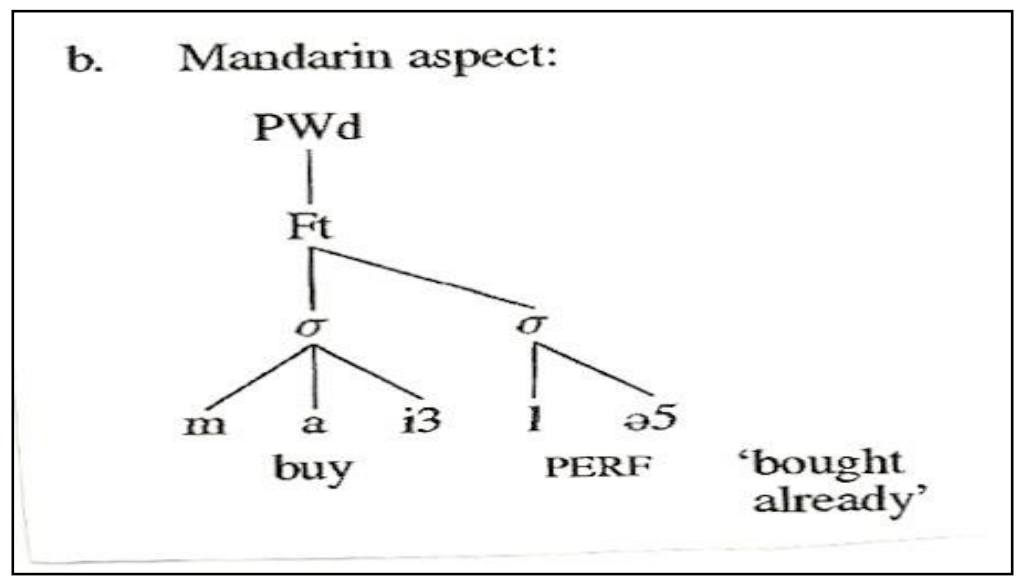

Figure 2. Mandarin Aspect

Since Mandarin does not allow adjunction to the PWd level (the structure in English for tense and agreement), it will not allow L2 learners of English to produce tense and agreement consistently. Goad et al. (2003) state that: "while tense and agreement features are underlyingly present in the IL grammar, learners are unable to reliably produce the corresponding forms because they cannot represent them prosodically in target-like fashion in 
outputs" (p. 246). This results in two predictions. The first is deletion across the board (ATB) for inflectional morphemes because Mandarin doesn't allow the prosodic structure of English tense and agreement in its grammar. The second is that inflectional morphemes will be deleted in a predictable pattern.

Based on the different tasks carried out, the participants showed that they were aware of agreement and tense morphology in English. Also, their interlanguage grammar has INFL-related properties such as nominative case assignment (100\%). However, their suppliance of the regular past tense morphology was only $(57 \%)$ and $3^{\text {rd }}$ person singular agreement was $(28 \%)$. A closer look into agreement morphology, the results were divided into two groups. The first group, consistent with the first prediction (ATB), only supplied $10 \%$ of agreement morphology. The second group supplied $49 \%$ of agreement morphology (consistent with the second prediction). Finally, Goad et al. (2003) conclude, based on their second prediction, inflectional morphemes will be deleted in a predictable variable pattern. If the attached inflectional morpheme can be analysed as stem internal (similar to Mandarin) and incorporated in the prosodic word structure, inflection will be supplied.

The studies mentioned above deal with the role of phonology on the production of inflection morphemes. However, they did not explore the effect of phonological universals on inflectional morphology. A look at different studies that examine the effect of phonological universals on the production of clusters in general is important. One study was conducted by Major (1996). He does not study any variation in morphological inflection, but he studies the acquisition of consonant clusters in L2 learner's speech in general with no reference to morphology. However, this study sheds some light on the phonological effects of production in general. He tests whether the interlanguage phonology of L2 learners abides by phonological universals or not. He looks at onset and coda clusters with two members only. Major (1996) collects the data from native speakers of Portuguese learning English as an L2. The consonant clusters selected in the different tasks are not found in the participants' native language. He tested whether the learners' production is target-like (correct) or non-target like (incorrect). For non-target like productions two factors were investigated: L1 transfer and language universals or what he calls developmental factors. The results of the study show that L2 learners' resort to both transfer and developmental factors to produce these consonant clusters. L2 learners transfer their syllable structure from their L1 to the L2. In addition, he claims that interlanguage phonology in adult second language learners is restricted to the same phonological universals as any natural language, therefore concluding that L2 learners abide by phonological universals.

\subsection{Studies on OCP}

Although not much research has documented the effects of the OCP on second language learners' production in the production of tense, Weinberger (1995) provides a reanalysis of previous studies' data that show OCP effects. Weinberger (1995) looks at Sounders (1987) study on monomorphemic variation in clusters in Japanese English. The results of the study indicate that Japanese learners of English delete $3^{\text {rd }}$ person /-s/ when the preceding segment is a coronal ( $75 \%$ deletion). The high rate of deletion in [coronal][coronal] shows an OCP 
violation of place. This prompts learners to reduce the cluster. Another study that Weinberger (1995) looked at was conducted by Young (1991). He tested L2 consonant deletion in plural marking. Chinese speakers tend to delete the /s/ plural in L2 English if the preceding segment was a nasal (42\%), sibilant (46\%) and a lateral (58\%). These adjacent segments are [coronal][coronal] which according to Weinberger violate the OCP. Weinberger's (1995) findings imply that L2 learners' deletion of the second member of the coda cluster is not due to $\mathrm{L} 1$ transfer, but rather to a universal like the OCP.

Recently, Edwards (2011) investigates the acquisition patterns of second language learners of English in the deletion patterns of $/ \mathrm{t}, \mathrm{d} /$. She examines whether L2 learners acquire the constraints (such as grammatical conditioning and phonological environment) on $/ \mathrm{t}, \mathrm{d} /$ deletion similar to native speakers of English. She takes 3 approaches in testing if L2 learners exhibit similar patterns to native speakers on /t,d/ deletion. She tests Labov's (1997) resyllabification approach, Guy's (1980) sonority approach and Guy and Boberg (1997) OCP approach. She collects data from 7 Mandarin speakers of English. She conducts two interviewers that are 6 months apart. Edwards (2011) uses variable rule analysis (VARBRUL) to analyse her data. She collected a total number of 1,789 tokens that consisted of CC or CCC word-final consonant clusters. Her findings indicate that four major constraints have a significant effect on $/ \mathrm{t}, \mathrm{d} /$ deletion in English as second language for native Mandarin speakers. The constraints are (from greatest to least effect): following linguistic environment, preceding linguistic environment, voicing agreement, and grammatical conditioning. Additional findings in the study do not show support for Labov's (1997) resyllabification approach. The results indicate that $/ 1 /$ and $/ \mathrm{r} /$ behave differently from Labov's (1997) findings. /1/ promotes deletion whereas $/ \mathrm{r} /$ has little effect on deletion. However, /j/ and /w/ promote deletion (similar to Labov's (1997) findings) but not strongly indicating that sonority can explain the deletion patterns better than resyllabification (Guy, 1980). Hansen Edwards also compared the effects of the preceding linguistic environment to Guy and Boberg's (1997) findings and the effect of the OCP.

Similarities on distinctive features on deletion have been the focus of the analysis. Edwards' (2011) findings did not confirm the OCP in action. The results of Edwards' (2011) study only support the deletion of $/ \mathrm{t}, \mathrm{d} /$ following nasals and stops and sibilants do not promote deletion. Finally, Hansen Edwards (2011) proposes that these Mandarin speakers of English have achieved native-like use of $/ \mathrm{t}, \mathrm{d} /$ deletion patterns. She states that $\mathrm{L} 1$ transfer, acquisition of grammatical inflection, and verb forms affect the acquisition of the constraints on $/ \mathrm{t}, \mathrm{d} /$ deletion similar to native speakers of English.

The above studies give support to the claim that phonological factors affect the variation of coda-forming inflectional morphology. However, a few questions remain unanswered. In Goad et al's (2003) study, the difference in PWd structure results in deletion or variability of inflectional morphology. However, if the target language and native language do not have similar PWd structures, and L2 learners still show variability, how can the study account for this variability? Another issue in this study is the number of utterances supplied for each category. The participants only supplied 28 utterances for regular past tense, 71 for irregular, and 201 utterances for agreement. Additional data is needed especially in past tense markings 
to further support their hypothesis.

Looking closer into Bayley's (1996) study, phonological factors play an important role in /t,d/ deletion. He argues that $/ \mathrm{t}, \mathrm{d} /$ are likely to be retained if preceded and/or followed by a sonorant. This shows that L2 learners prefer adjacent sounds to be distinct from one another. Edwards (2011) addresses important questions on patterns of $/ \mathrm{t}, \mathrm{d} /$ deletion in L2 English. However, her study focuses on constraints that govern the variation patterns. The tokens collected in her study are mainly monomorphemes and very few tokens of bi-morphemes. She investigates deletion patterns. She examines whether or not L2 learners acquire $/ \mathrm{t}, \mathrm{d} /$ deletion patterns similar to native speakers of English. The low number of bi-morphemic tokens makes it difficult to see if phonology plays a role in morphological variability.

Previous research does not seem to account for why second language learners are deleting the morphological $/ \mathrm{t}, \mathrm{d} /$. There are some issues that need to be addressed. The first issue is the native language of the participants. In Bayley's (1996) and Goad et al.'s (2003) study, the native language of the participants was controlled. This control in native language background helps in predicting learner's errors that result from L1 transfer. In Solt et al's (2004) study, the participants had different L1 backgrounds. Being so, it is difficult to predict which errors the participants make are due to transfer or some other phenomenon.

In addition, Solt et al. (2004) conclude that L2 learners are less likely to perceive non-syllabic allomorphs /t, $\mathrm{d} /$ than the syllabic allomorph [əd] because [əd] is more salient (which is shown in the data). However, when looking at non-syllabic allomorphs, the results show that high proficiency learners perceive $[\mathrm{t}]$ better than [d] although a voiced segment is more salient than a voiceless segment (Solt et al., 2004). An alternative way to analyse Solt et al's (2004) data is not to look at syllabicity effects, but to look into the types of codas that formed with the addition of the past tense inflection. Also, it is important to see if the formed coda contains a singleton consonant or a consonant cluster and to investigate the properties of the coda clusters. For example, if the addition of the regular past tense morpheme resulted in a cluster that contained a stop + stop cluster like 'sto[pt]' or a fricative + stop cluster ' $\mathrm{ki}[\mathrm{st}]$ ' versus the extra syllabic allomorph 'lan[dəd]', would L2 learners produce them differently? It is important to examine whether L2 learners treat each cluster differently or not depending on its properties.

This leads to the search for further explanation on L2 learners' production of the regular past tense verb in L2 English. This study focuses on exploring if phonological universals can account for L2 learners' morphological variability in L2 English. The following section addresses the research question that might account for this variability.

\subsection{Research Question}

The phonological factors mentioned above were not to account for many of the questions presented in the literature. A different approach would be to look at phonological universals that might contribute to the variability. Although much research has been conducted on phonological universals and their effect on L2 phonology, the link between phonological universals and inflectional morphemes has rarely been made. To provide a better 
understanding of the variability in L2 English past tense production, I examine the impact of the OCP on learners' ability to produce target-like regular English past tense morphology. In this study, I address the following research question:

To what extent does the Obligatory Contour Principle impact the production of the regular past tense morpheme in L2 English?

\section{Method}

\subsection{Participants}

Twenty=two native Arabic speakers from Jeddah, Saudi Arabia who are enrolled in ESL classes were tested on the production of the regular English past tense verb. They all speak one dialect: Hijazi Arabic (spoken in the Western province of Saudi Arabia). The participants were divided into three groups according to their proficiency level (low, $n=7$, intermediate, $n=9$, and high, $n=6$ ). Their placement in the three proficiency levels was based on their level placement in the English Language Institute at George Mason University. For the low proficiency group, they were enrolled in mid-beginning classes. For the intermediate proficiency group, they are enrolled in high intermediate classes and for the high proficiency group they are enrolled in High advanced classes. Table 2 below summarizes the participants' demographic information. In addition, 9 native speakers of English were used as a control group.

Table 2. Participants' demographic information

\begin{tabular}{lllll}
\hline & $\begin{array}{l}\text { Mean Age of } \\
\text { Onset } \\
\text { years) }\end{array}$ & $\begin{array}{l}\text { Mean LOR } \\
\text { (in months) }\end{array}$ & Learning Method & Other languages \\
\hline $\begin{array}{l}\text { Low Proficiency } \\
\text { Interm. }\end{array}$ & 9.6 & 14 & & None \\
Proficiency & 8.3 & 12 & $\begin{array}{l}\text { None } \\
\text { Academic and } \\
\text { naturalistic }\end{array}$ & $\begin{array}{l}\text { One participant } \\
\text { reported German } \\
\text { as another } \\
\text { High Proficiency }\end{array}$ \\
& & 15 & & spoken language \\
\hline
\end{tabular}

\subsection{Experiment}

An elicited production task was used to obtain target clusters in English. The participants were asked to read sentences that consisted of regular past tense verbs. In order to rule out orthographic interference, the participants were asked to place the verb in parentheses in the past tense. Examples of test sentences are shown below (see Appendix A for the full list of elicitation sentences).

(1) John (stop) his speech

(2) Bill and Mary (use) her exam

A total of 26 regular past tense verbs were tested. The selected verbs targeted certain types of 
codas formed $(\mathrm{Obs}+/ \mathrm{t} /$ or $/ \mathrm{d} /)$ and $(\mathrm{Obs}+/ \partial \mathrm{d} /)$. The selected verbs either matched in manner such as stop $+/ \mathrm{t}, \mathrm{d} /$ or it did not, such as fricative $+/ \mathrm{t}, \mathrm{d} /$. Table 3 below shows a complete list of the targeted past tense verbs and the clusters formed. Each participant was audio-recorded using a digital recorder in a soundproof lab.

Table 3. Past tense verbs used in the production task divided by allomorph

\begin{tabular}{cll}
\hline Past tense morpheme & Verb & Cluster \\
\hline$[\mathrm{t}]$ & stopped, dropped, & {$[\mathrm{pt}]$} \\
& locked, baked & {$[\mathrm{kt}]$} \\
& kissed, missed & {$[\mathrm{st}]$} \\
& laughed, bluffed & {$[\mathrm{ft}]$} \\
& washed, crashed & {$[\mathrm{ft}]$} \\
& watched & {$[\mathrm{t} \mathrm{t}]$} \\
& described, bribed & {$[\mathrm{bd}]$} \\
mugged, hugged & {$[\mathrm{gd}]$} \\
& advise, use & {$[\mathrm{zd}]$} \\
& clothe, bathe & {$[$ dd] } \\
& judge, damage & {$[\mathrm{d} z \mathrm{~d}]$} \\
& knit, land, head & No cluster \\
\hline
\end{tabular}

Table 3 above shows that the addition of the English past tense morpheme results in either stop + stop cluster 'sto[pt]' or fricative + stop clusters ki[st]. An important note here is that all the participants in the study speak Hijazi Arabic. This dialect allows word-final clusters of stop + stop and fricative + stop. Hijazi Arabic has words like kata[pt] 'I wrote', ra[pt] 'to tie', he[gt] 'I exploded', ge[st] 'I tried on'. Some that are morphological, and others are not. Based on this fact, one expects positive transfer of the syllable structure from the participants' L1 to the $\mathrm{L} 2$.

\section{Results}

The production task elicited a total of 572 tokens of regular past tense verb productions from the L2 participants. 176 tokens were stop $+/ \mathrm{t}, \mathrm{d} /$ clusters, 330 tokens were fricative $+/ \mathrm{t}, \mathrm{d} /$ clusters and 66 were [əd] allomorph. Table 4 shows the classification of the cluster types analysed in the study.

Table 4. Classification of cluster types

\begin{tabular}{lll}
\hline & Definition & Example \\
\hline Type A & The addition of the regular past tense & sto[pt] \\
Stop + stop & will result in a cluster of stop + stop & bri[bd] \\
Type B & The addition of the regular past tense & ki[st] \\
Fricative + stop & will result in a cluster of fricative + stop & mo[vd] \\
Type C & The addition of the regular past tense & lan[dəd] \\
Syllabic & will result in no cluster, but an addition & hea[dəd] \\
& of a syllable & \\
\hline
\end{tabular}


Of the 66 tokens from type C [əd], 22 tokens were excluded from the analysis. These tokens illustrate the production of the verb 'knit'. The exclusion was based on native speakers' productions where native speakers showed a variation in their production kni[t] vs. kni[təd]. Similar to native speakers, the L2 participants showed variation in the production as well. Therefore, a total number of 550 tokens were analysed in the study. Table 5 below summarizes the percentage of deletion by proficiency level and cluster type.

Table 5. Percentage of deletion by proficiency level and cluster type

\begin{tabular}{lllll}
\hline & Low & Intermediate & High & Native \\
\hline $\mathrm{a}=$ stop+/t,d/ & 57.14 & 40.27 & 22.91 & 0 \\
$\mathrm{~b}=$ fricative+/t,/d & 25.71 & 6.6 & 11.11 & 0 \\
$\mathrm{C}=$ syllabic & 28.57 & 18.51 & 11.11 & 0 \\
\hline
\end{tabular}

Table 6 below shows the actual output from the participants by proficiency level and type A clusters ( stop $+/ \mathrm{t}, \mathrm{d} /)$.

Table 6. Actual production from participants by proficiency level and type A clusters

\begin{tabular}{llllll}
\hline Participant & Prof. Level & sto[pt] & bri[bd] & lo[kt] & mu[gd] \\
\hline LP-1 & Low & sto[p] & bri[b] & lo[k] & mu[g] \\
MP-1 & Intermediate & sto[pt] & bri[p] & lo[k] & mu[gd] \\
HP-1 & High & sto[pt] & bri[bd] & lo[kt] & mu[gd] \\
\hline
\end{tabular}

As shown above in Table 6, the participant LP-1 is a low proficiency speaker. The participant deletes the $/ \mathrm{t}, \mathrm{d} /$ when faced with a type A cluster (stop + stop). For MP-1, this participant is an intermediate proficiency learner. He/she shows variation in the production of the inflectional morphology. The participant only deletes in two cases out of 4. Finally, the high proficiency speaker HP-1 produces all the clusters correctly. Table 7 below shows the actual participants' production by proficiency level and cluster type $B$ (fricative $+/ t, d /$ ).

Table 7. Actual production from participants by proficiency level and type B clusters

\begin{tabular}{llllll}
\hline Participant & Prof. Level & $\mathrm{lau}[\mathrm{ft}]$ & $\mathrm{ki}[\mathrm{st}]$ & $\mathrm{mo}[\mathrm{vd}]$ & $\mathrm{use}[\mathrm{zd}]$ \\
\hline LP-1 & Low & $\mathrm{lau}[\mathrm{v}]$ & $\mathrm{ki}[\mathrm{st}]$ & $\mathrm{mo}[\mathrm{vd}]$ & $\mathrm{use}[\mathrm{z}]$ \\
MP-1 & Intermediate & $\mathrm{lau}[\mathrm{ft}]$ & $\mathrm{ki}[\mathrm{st}]$ & $\mathrm{mo}[\mathrm{vd}]$ & $\mathrm{use}[\mathrm{zd}]$ \\
HP-1 & High & $\mathrm{lau}[\mathrm{ft}]$ & $\mathrm{ki}[\mathrm{st}]$ & $\mathrm{mo}[\mathrm{vd}]$ & $\mathrm{use}[\mathrm{zd}]$ \\
\hline
\end{tabular}

Table 7 above shows that the participant LP-1 is deleting the morphology in some words and not in others. LP-1 is showing variation in the production of $/ \mathrm{t}, \mathrm{d} /$ when preceded by a fricative. However, the participants MP-1 and HP-1 do not show any variation in their production of target-like morphology. They produce all fricative + stop clusters correctly. On the other hand, there are some intermediate proficiency speakers that show variation in their production. For example, participant MP-2 produced the verb 'kissed' as ki[s] and 'laughed' as lau[f]. Finally, Table 8 below shows the production of syllabic allomorphs. These examples show that the verb does not end with a cluster with the addition of the regular past tense morphology. It is mainly an addition of an extra syllable. In spite of this, participants still showed variation in their production. 


\section{I Macrothink}

International Journal of Linguistics

ISSN 1948-5425

2021, Vol. 13, No. 6

Table 8. Actual production from participants by proficiency level and extra-syllabic [əd]

\begin{tabular}{llll}
\hline Participant & Prof. Level & hea[dəd] & lan[dəd] \\
\hline LP-1 & Low & hea[d] & lan[dəd] \\
MP-1 & Intermediate & hea[dəd] & lan[dəd] \\
HP-1 & High & hea[d] & lan[dəd] \\
\hline
\end{tabular}

\subsection{Production Task Results}

The results were coded according to learners' production to see whether they produced the correct form or repaired the cluster (epenthesis or deletion). However, the analysis only included where the participants showed deletion. The reason why the analysis only included deletion and not epenthesis is that only 4 tokens were epenthesized, so they were discarded from the analysis. In addition, the analysis included the effect of proficiency level and cluster type (where the cluster formed matches in manner or not) on their production. The results of the study were analysed using mixed effects ANOVA on SAS. For each analysis, proficiency level (low, intermediate, high) and cluster type $(a=s t o p+/ t, d /, b=$ fricative+/t,d/, c=[əd]) were the fixed effects. The actual verb and speaker were the random effects. Main effects of proficiency level and cluster type as well as interaction effects are presented below. Post hoc Tukey tests were performed to test the significance between proficiency and cluster type differences.

Beginning with the analysis of deletion, the main effect of proficiency level is statistically significant $(\mathrm{F}=3.56, \mathrm{p}<.05)$. The post hoc analysis indicates that this effect is due to the difference between the low proficiency and high proficiency groups. Figure 3 below summarizes the percentage of overall deletion by proficiency level. The overall deletion across the three different verb groups is highest in low proficiency speakers (35\%). The repairs decrease when the proficiency level is higher (intermediate $=18.37 \%$, high $=14.74 \%$ ). Finally, the native control group showed $0 \%$ deletion.

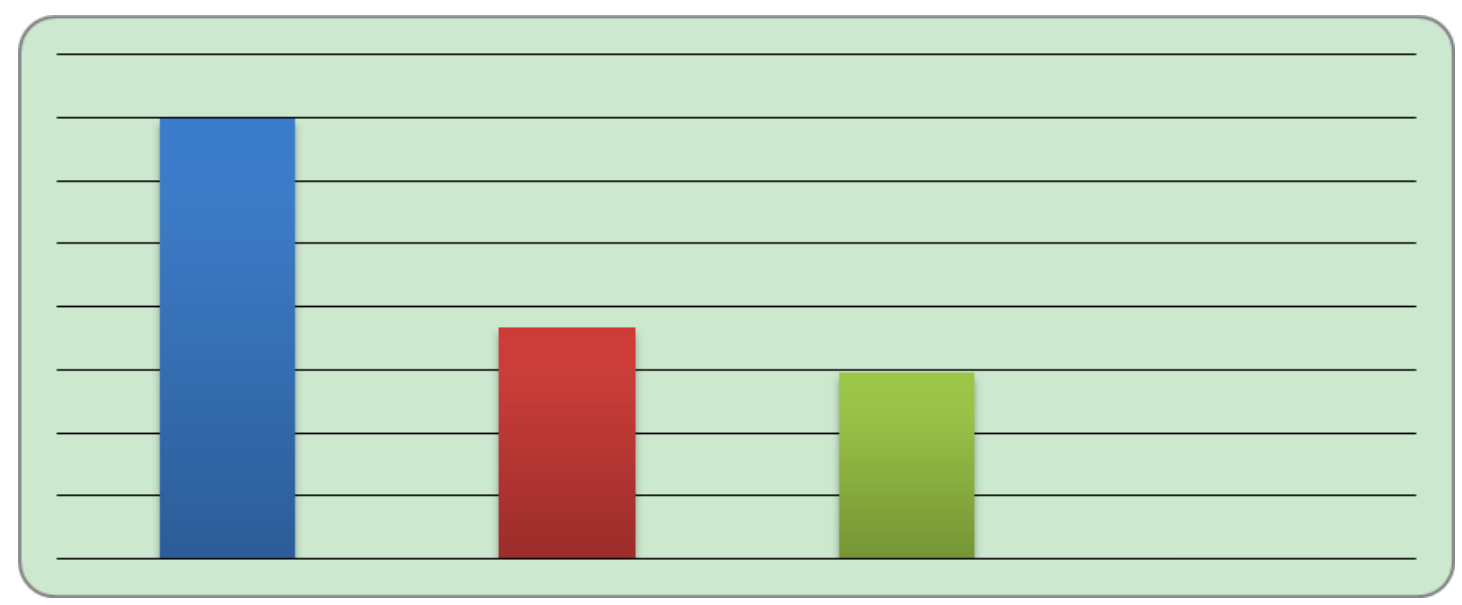

Figure 3. Percentage of deletion by proficiency level

In addition to proficiency level, the effect of cluster type ( $a, b$ or $c$ ) on deletion is found to be statistically significant $(\mathrm{F}=4.83, \mathrm{p}<.01)$. Where stops $+/ \mathrm{t}, \mathrm{d} /$ have a higher percentage of 
deletion than fricatives $+/ \mathrm{t}, \mathrm{d} /$. The interaction between proficiency level and cluster type is not statistically significant $(\mathrm{F}=.43, \mathrm{p}=.785)$. Figure 4 below shows the percentage of deletion in each cluster type.

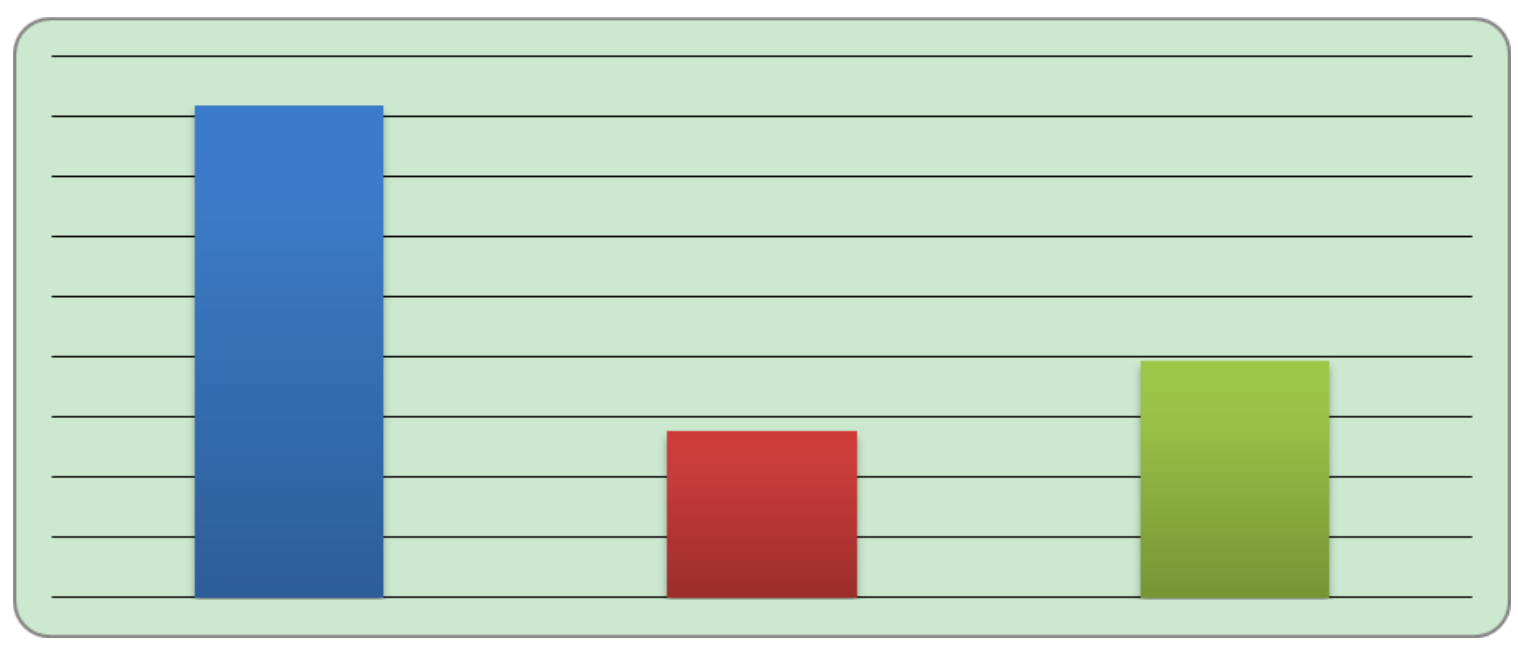

Figure 4. Percentage of cluster repair by cluster type

A look at the results above indicates that there is an overall tendency to repair clusters from type A (stop $+/ \mathrm{t}, \mathrm{d} /$ ) than types B (fricative $+/ \mathrm{t}, \mathrm{d} /$ ) and $\mathrm{C}$ (syllabic) regardless of proficiency level. In addition, low proficiency learners tend to repair clusters at a higher rate than the intermediate and high groups.

\section{Discussion}

It has been well been established in the literature that the OCP occurs in many natural languages; Arabic (McCarthy, 1988), Latin (Kenstowicz, 1994; Torre, 2003) and Japanese (Yip, 1988) are just a few examples. Arabic prohibits the occurrence of two identical adjacent consonants in the root (McCarthy, 1988). For example, the root ktb 'to wrote' is allowed, but a root like *ssm is not allowed. However, smm 'to poison' does exist in Arabic. McCarthy (1986) concludes that in a triconsonantal roots, $\mathrm{C}_{1}$ and $\mathrm{C}_{2}$ cannot be identical, but $\mathrm{C}_{2}$ and $\mathrm{C}_{3}$ can. He attributes this phenomenon autosegmental spreading. In addition, McCarthy (1988) claims that the OCP does not only affect segments and supra-segmental features, but it also active between non-identical segments sharing a feature. He investigated the feature [place] in OCP. He divided place features in OCP into [labial], [coronal], [dorsal] and [pharyngeal]. He states that in Arabic a root like $* f t b$ does not occur because /f/ and /b/ are both labials therefore violating OCP place.

Another example of OCP restrictions in relation to features is found in manner. Manner features are divided into: [consonantal], [sonorant], [continuant], [nasal], [liquid], [approximant], and [lateral] (van Goch, 2010). Evidence of OCP restrictions in relation to manner is found in Latin. The example below is taken from Kenstowicz (1994)(found in Van der Torre, 2003). The Latin adjectival suffix -alis dissimilates to -aris when the proceeding stem contains /l/: nav + alis $\rightarrow$ navalis 'naval' but sol+alis $\rightarrow$ solaris 'solar'. Finally, Japanese shows some evidence of OCP restrictions on voice. Yip (1988) investigated rule blocking in 
Japanese (Rendaku). The process is shown in voicing the second element of a compound. An example (taken from Yip, 1988) is shown below:

(3) a. maki + sushi $\rightarrow$ makizushi 'rolled sushi'

b. kami + kaze $\rightarrow$ kamikaze 'divine wind'

In (3.a) above /s/ becomes /z/ i.e. voiced and in (3.b) the voiceless /k/ in kamikaze remains voiceless because the second element is already a voiced segment /z/. The examples above show that the OCP exists in many natural languages and not only on segments, but the OCP is operable on features as well.

Looking back at the data in this paper, there are two different methods to analyse the data. First, if we assume that L2 learners do not violate OCP place, we would expect to find a higher rate of repair in group B (where all clusters are coronal + coronal). However, this is not the case. L2 learners repair clusters that are coronal + coronal $(13.93 \%)$ at a lower rate than labials/velars + coronal $(41 \%)$. This repair can be seen across all three proficiency levels. Second, the results of the study indicate that OCP manner is operable in these L2 learners. L2 learners repair the cluster when the preceding segment matches in manner with $/ \mathrm{t}, \mathrm{d} /$. The highest repair of clusters is seen when the preceding segment is from group A (stops $+/ \mathrm{t}, \mathrm{d} /)^{-}$ $41 \%$. When the preceding segment does not match in manner with $/ \mathrm{t}, \mathrm{d} /$, the percentage of cluster repair decreases (13.93\%) regardless of proficiency level. The pattern of cluster repair is seen across all three proficiency levels. What is interesting to note here is that Arabic allows clusters of stop+stop. This dialect allows word-final clusters of stop + stop and fricative + stop. Hijazi Arabic has words like kata[pt] 'I wrote', ra[pt] 'to tie', he[gt] 'I exploded', ge[st] 'I tried on'. Some that are morphological, and others are not. If L1 transfer of syllable structure played a role in the production, then we would expect to find no problems with most of the verbs produced. However, since Hijazi Arabic allows for many of the word-final clusters used in the study, then transfer has no effect on the production of the past tense verbs. Therefore, the results of the study show that Arabic L2 learners of English do not violate OCP manner.

One interesting observation is the production of syllabic allomorphs. The pattern observed in the study (regardless of proficiency level) is that the participants repair clusters that violate OCP manner (stops $+/ t, d /$ ). They repair less when the clusters are fricatives $+/ t, d /$ ). When we look at their production of the syllabic allomorphs, we find that there is an increase in the percentage of repair. Table 3 above shows that low and intermediate proficiency groups delete the final $/ \mathrm{t}, \mathrm{d} /$ when there is no cluster. They would produce hea[d] instead of hea[dId]. This pattern is not observed in high proficiency learners. These results might indicate that low and intermediate proficiency learners follow the pattern observed in child language acquisition. According to Akhtar and Tomasello (1997), children are productive in using -ing than -ed. The assumption is that -ed has more than one allomorph to be acquired that is why it takes longer for children to learn. In addition, Hohenstein and Akhtar (2007) studied children adding inflections (-ing and -ed) to novel verbs. Their results indicate that older children drop 
-ed more than younger children. The pattern in L2 learners seems to be similar to children acquiring English as their first language.

To get a better understanding of the learner's interlanguage grammar with respect to past tense production, one must consider methodological implications (Wolfram, 1985). First, only one task was conducted to test the impact of OCP on L2 learners' production of the English regular past tense. A spontaneous production task in addition to the task used in this study, might give us a better understanding of the learners' IL grammar. In addition to production, a perception task would also help us determine how the IL grammar is. By comparing production and perception, we can determine if the L2 learner perceives the past tense but cannot produce it, or that L2 learner cannot produce what they cannot perceive. If the perception task results show us that L2 learners can perceive the past tense, but cannot produce it, then we would know that phonological factors play a major role in their production.

\section{Conclusion}

The results in this study support that OCP manner is operable in these L2 learners. The percentage of deletion when the preceding segment matched in manner (stops $+/ \mathrm{t}, \mathrm{d} /$ ) indicates that L2 learners do not violate OCP manner. Even though the participants in the study have clusters in their native language that match in manner. Together these results indicate that L1 transfer is not the only source of difficulty in the production of past tense morphology, and that the abstract feature of tense is problematic, particularly at the early stages of ESL development. More data needs to be gathered in both production and perception tasks to better understand learners' interlanguage. In addition, further questions need to be addressed such as the production of other morphemes in English such as $-\mathrm{s}$ third person singular. Overall, this study may serve as a starting point to relate morphological variability and phonological universals in L2 production.

\section{References}

Akhtar, N., \& Tomasello, M. (1997). Young children's productivity with word order and verb morphology. Developmental psychology, 33(6), 952.

Bayley, R. (1996). Competing constraints on variation in the speech of adult Chinese learners of English. Second Language Acquisition and Linguistic Variation, 97120.

Edwards, J. G. H. (2011). Deletion of/t, d/and the Acquisition of Linguistic Variation by Second Language Learners of English. Language Learning, 61(4), 1256-1301.

Goad, H., White, L., \& Steele, J. (2003). Missing Inflection in L2 Acquisition: Defective Syntax or LI-Constrained Prosodic Representations?. Canadian Journal of Linguistics/Revue Canadienne de Linguistique, 48(3-4), 243-263.

Grondin, N., \& White, L. (1996). Functional categories in child L2 acquisition of French. Language Acquisition, 5(1), 1-34. 


\section{I Macrothink}

International Journal of Linguistics

ISSN 1948-5425

2021, Vol. 13, No. 6

Guy, G. (1980). Variation in the group and the individual: The case of final stop deletion. In Locating language in time and space (pp. 1-36). Academic Press.

Guy, G. R., \& Boberg, C. (1997). Inherent variability and the obligatory contour principle. Language Variation and Change, 9(2), 149-164.

Hawkins, R., \& Chan, C. Y.-h. (1997). The partial availability of Universal Grammar in second language acquisition: The 'failed functional features hypothesis'. Second Language Research, 13(3), 187-226.

Haznedar, B., \& Schwartz, B. D. (1997). Are there optional infinitives in child L2 acquisition. Proceedings of the 21 st annual Boston University conference on language development.

Hohenstein, J., \& Akhtar, N. (2007). Two-year-olds' productivity with verbal inflections. Journal of Child Language, 34(4), 861-873.

Holes, C. (2004). Modern Arabic: Structures, functions, and varieties. Georgetown University Press.

Kenstowicz, M. J. (1994). Phonology in generative grammar (Vol. 7). Blackwell Cambridge, MA.

Kreidler, C. W. (2008). The pronunciation of English: A course book. John Wiley \& Sons.

Lardiere, D. (2003). Second language knowledge of [ \pm past] vs.[ \pm finite]. Proceedings of the 6th generative approaches to second language acquisition conference (GASLA 2002).

Major, R. C. (1996). Markedness in second language acquisition of consonant clusters. Second Language Acquisition and Linguistic Variation, 75-96.

McCarthy, J. J. (1986). OCP effects: Gemination and antigemination. Linguistic Inquiry, 207-263.

McCarthy, J. J. (1988). Feature geometry and dependency: A review. Phonetica, 45(2-4), 84-108.

Meisel, J. M. (1991). Principles of Universal Grammar and strategies of language use: On some similarities and differences between first and second language acquisition. Point-counterpoint: Universal Grammar in the Second Language, 231-276.

Prévost, P., \& White, L. (2000). Missing surface inflection or impairment in second language acquisition? Evidence from tense and agreement. Second Language Research, 16(2), 103-133.

Ryding, K. C. (2005). A reference grammar of modern standard Arabic. Cambridge University Press.

Solt, S., Pugach, Y., Klein, E. C., Adams, K., Stoyneshka, I., \& Rose, T. (2004). L2 perception and production of the English regular past: Evidence of phonological effects. BUCLD 28: Proceedings of the 28th annual Boston University Conference on Language Development. 


\section{Macrothink}

International Journal of Linguistics

ISSN 1948-5425

2021, Vol. 13, No. 6

Sounders, N. J. (1987). Morphophonemic variation in clusters in Japanese English. Language learning, 37(2), 247-272.

Torre, E. J. v. d. (2003). Dutch sonorants: The role of place of articulation in phonotactics. Utrecht: LOT.

Vainikka, A., \& Young-Scholten, M. (1996). Gradual development of L2 phrase structure. Second Language Research, 12(1), 7-39.

van Goch, W. (2010). The Obligatory Contour Principle, consonant co-occurrence restrictions in Dutch

Weinberger, S. (1995, May). Maintaining Distinctions: The OCP in L2 Phonology. Presented at GASLA 95 (Generative Approaches to Second Language Acquisition), New York.

Wolfram, W. (1985). Variability in tense marking: A case for the obvious. Language Learning, 35(2), 229-253.

Yip, M. (1988). The Obligatory Contour Principle and phonological rules: A loss of identity. Linguistic Inquiry, 19(1), 65-100.

Young, R. (1991). Variation in interlanguage morphology (Vol. 1). Peter Lang Pub Incorporated.

\section{Appendix A. List of Test Sentences}

1. John (stop) his speech.

2. Mary (drop) her phone.

3. Bill's grandmother (describe) him.

4. $\mathrm{He}$ (bribe) him.

5. Sally (knit) her sweater.

6. Sally (lock) her room.

7. She (bake) her cake.

8. She (land) her job.

9. I (head) her way.

10. I (hug) her hard.

11. They (mug) him.

12. I (kiss) her hand.

13. Mary (miss) her.

14. Her parents (advise) her. 
15. Bill and Mary (use) her exam.

16. She (bathe) her baby.

17. She (clothe) her baby.

18. They (laugh) him out.

19. $\mathrm{He}$ (bluff) his way.

20. John (save) her life.

21. The movie (move) her feelings.

22. $\mathrm{He}$ (wash) his cat.

23. She (crash) her car.

24. $\mathrm{He}$ (watch) his sister.

25. $\mathrm{He}$ (judge) his contestants.

26. $\mathrm{He}$ (damage) his fridge.

\section{Copyrights}

Copyright for this article is retained by the author(s), with first publication rights granted to the journal.

This is an open-access article distributed under the terms and conditions of the Creative Commons Attribution license (http://creativecommons.org/licenses/by/4.0/) 